\title{
Spatiotemporally Restricted Developmental Alterations in the Anterior and Secondary Heart Fields Cause Distinct Conotruncal Heart Defects
}

\author{
Mayu Narematsu and Yuji Nakajima
}

\begin{abstract}
During the early heart development, heart outflow tract elongates by the addition of cardiomyocytes from the anterior heart field (AHF)/secondary heart field (SHF). Dye-marking experiments in early chick embryos clarified that each $\mathrm{AHF} / \mathrm{SHF}$ migrates to distinct conotruncal regions. Local administration of retinoic acid to the AHF/SHF causes distinct conotruncal heart defects in a region and stage dependent manner. For example, impaired development of $\mathrm{AHF}$ at $\mathrm{HH}$ stage 12 (corresponding to Carnegie stages 10-11 in human embryos) causes dextroposed aorta including transposition of the great arteries (TGA), while SHF at HH stage 12 persistent truncus arteriosus (PTA). Our results indicated that the abnormal development of certain $\mathrm{AHF} / \mathrm{SHF}$ at certain stages causes specific spectrum of conotruncal heart defects.
\end{abstract}

\section{Keywords}

Second heart field - Heart outflow tract - Transposition of great arteries · Congenital heart defects $\cdot$ Retinoic acid

Developmental alterations of the heart outflow tract (OFT) cause conotruncal heart defects (CTHDs), which are often diagnosed in infants with congenital heart defects. During the early heart development, the OFT elongates by the addition of

\footnotetext{
M. Narematsu $\cdot$ Y. Nakajima $(\bowtie)$

Department of Anatomy and Cell Biology, Graduate School of Medicine,

Osaka City University, Osaka, Japan

e-mail: narematsu@med.osaka-cu.ac.jp; yuji@med.osaka-cu.ac.jp 
Table 59.1 Conotruncal heart defects produced by local administration of RA to the AHF or SHF at early looped-heart stage in chick embryonic hearts

\begin{tabular}{l|l|l|}
\hline RA addition & At stage 12 & At stage 14 \\
\hline To AHF & TGA, DORV & PTA \\
\hline To SHF & PTA & PTA, DORV
\end{tabular}

${ }^{a}$ Corresponding to embryonic day (ED) 8.5 in mouse and Carnegie stage 10 in human

${ }^{\mathrm{b}} \mathrm{ED} 9.0$ in mouse and Carnegie stage 11 in human

cardiomyocytes from the second lineage of heart-forming regions, which reside in the first and second pharyngeal arches (anterior heart field [AHF]) as well as in the splanchnic mesoderm of the pericardial coelom in the posterior pharyngeal arches (secondary heart field [SHF]) [1]. As the arterial pole moves in the anterior-to-posterior (cranial-to-caudal) direction, the AHF is first added to the OFT followed by the SHF. Therefore, abnormal development of certain parts of the AHF or SHF at certain stages may cause specific CTHDs.

Dye-marking experiments in chick embryos at the early looped-heart stage showed that the right and left AHFs migrate ipsilaterally to form the proximal OFT, whereas SHFs migrate rotationally to form the distal OFT beneath the semilunar valves [2]. The results indicated that each AHF/SHF migrates to generate distinct conotruncal regions.

Retinoic acid (RA) is a potent teratogen to induce CTHDs. Local administration of RA to the AHF in chick embryos at early looped-heart stage (stage 12) caused a truncated OFT, thereby resulting in transposition of the great arteries (TGA) and double outlet right ventricle (DORV) (Table 59.1) [3]. The left AHF was more sensitive to RA in the development of TGA. Accordingly, the proximal OFT, especially the subpulmonic region, may play a role in conotruncal rotation to establish the left ventricle-to-aortic connection [4]. Persistent truncus arteriosus (PTA) occurred when RA was added to the SHF at stage 12 as well as to the AHF/SHF at stage 14 (Table 59.1). Accordingly, normal development of the distal OFT is necessary for conotruncal septation involving the aortico-pulmonary septum, a derivative of the cardiac neural crest. In conclusion, AHF at the early looped-heart stage, corresponding to Carnegie Stages 10-11 in human embryos, is the region responsible, and impediment of which causes a dextroposed aorta including TGA.

\section{References}

1. Nakajima Y. Second lineage of heart forming region provides new understanding of conotruncal heart defects. Congenit Anom (Kyoto). 2010;50:8-14.

2. Takahashi M, Terasako Y, Yanagawa N, et al. Myocardial progenitors in the pharyngeal regions migrate to distinct conotruncal regions. Dev Dyn. 2012;241:284-93.

3. Narematsu M, Kamimura T, Yamagishi T, et al. Impaired development of left anterior heart field by ectopic retinoic acid causes transposition of the great arteries. J Am Heart Assoc. 2015;4 https://doi.org/10.1161/JAHA.115.001889.

4. Nakajima Y. Mechanism responsible for D-transposition of the great arteries: is this part of the spectrum of right isomerism? Congenit Anom (Kyoto). 2016;56:196-202. 
Open Access This chapter is licensed under the terms of the Creative Commons Attribution 4.0 International License (http://creativecommons.org/licenses/by/4.0/), which permits use, sharing, adaptation, distribution and reproduction in any medium or format, as long as you give appropriate credit to the original author(s) and the source, provide a link to the Creative Commons license and indicate if changes were made.

The images or other third party material in this chapter are included in the chapter's Creative Commons license, unless indicated otherwise in a credit line to the material. If material is not included in the chapter's Creative Commons license and your intended use is not permitted by statutory regulation or exceeds the permitted use, you will need to obtain permission directly from the copyright holder. 